\title{
ANÁLISE QUALIQUANTITATIVA DA ARBORIZAÇÃO E INFRAESTRUTURA DE PRAÇAS DA CIDADE DE PONTA GROSSA-PR.
}

\author{
Zíngara Rocio dos Santos Eurich¹, Silvia Méri Carvalho²
}

\section{RESUMO}

É fundamental para uma cidade a presença de espaços livres de edificação (parques, praças entre outros), pois esses espaços têm a função de proporcionar chances de lazer e aumento da qualidade de vida para a população. Nessa afirmativa as praças quando bem administrada, tornam-se um espaço importante para as cidades. Com isso se propôs avaliar qualiquantitativamente os indivíduos arbóreos e a infraestrutura de trinta e quatro praças da cidade de Ponta Grossa-PR. No levantamento da arborização foi contabilizado um total de 1.467 indivíduos arbóreos, onde o predomínio foi de espécies exóticas (63,1\%). Quanto ao levantamento da infraestrutura, verificou-se que as estruturas mais frequentes foram: caminhos $(85,2 \%)$, iluminação $(79,4 \%)$, bancos $(73,5 \%)$ e telefones públicos $(47,0 \%)$. 0 Complexo Ambiental Governador Manuel Ribas, praça Barão do Rio Branco, Bispo Antônio Mazzarotto e Simão Bolivar, foram as praças com mais atrativos para todas as idades, como parque infantil, quadras, pista para caminhada, academia para terceira idade, entre outros equipamentos. Já as praças Cel. Cristiano Justus Júnior e Clube Serra de Ponta Grossa não apresentaram nenhum equipamento. A partir dos resultados observa-se um cenário heterogêneo em todos os itens analisados, visto que há praças que contam com ampla infraestrutura e outras sem nenhum equipamento disponível.

Palavras-chave: Espaço Público; Espaço Livre; Espécies Exóticas e Nativas; Equipamentos.

Recebido em 05.04.2013 e aceito em 08.05.2015

1 Doutoranda no Programa de Pós-Graduação em Geografia da Universidade Estadual de Ponta Grossa

2 Doutora docente do Departamento de Geografia e do Programa de Pós-Graduação em Geografia da Universidade Estadual de Ponta Grossa. 


\section{QUANTITATIVE-QUALITATIVE EVALUATION OF THE SQUARES' AFFORESTATION AND INFRASTRUCTURE FROM THE CITY OF PONTA GROSSA-PR.}

\section{ABSTRACT}

It is essential for a city the presence of free building spaces (parks, squares etc.), because these spaces are meant to provide chances for leisure and increased quality of life for the population. In this statement, squares become an important space for cities, when wellmanaged. Thus, there were proposed to evaluate qualitative and quantitatively the afforestation and infrastructure of thirty-four squares of the city of Ponta Grossa-PR. In the survey of afforestation there was counted a total of 1,467 individual trees, where there was the predominance of exotic species (63.1\%). As for the lifting of the infrastructure one checked that the most frequently structures were the ways (85.2\%), lighting (79.4\%), banks (73.5\%) and public phones (47.0\%). The environmental complex Governador Manuel Ribas, squares Barão do Rio Branco, Bispo Antônio Mazzarotto e Simão Bolivar, were more giftled structures, with charms for all the cities, like children's, playground, blocks, trace forwalk, for third age, between other equipments. Already the squares Cel. Cristiano Justus Júnior and the square Clube Serra de Ponta Grossa the did not present any equipament. From the results a heterogeneous scenerys watched in all the analysed items, as there are squares that have extensive infrastructure and some areas have not any available equipament.

Keywords: Public Space; Free Space; Native and Exotic Species; Equipments.

\section{INTRODUÇÃO}

Os espaços públicos de suma importância para as cidades são tão antigos quanto às próprias cidades. Desde muito antes do século XX, vários autores já se dedicavam a estudar os espaços públicos nas suas mais diferentes estruturações e configurações. Em cada momento histórico eram verificadas influências, ora pelo poder da igreja, ora por influências econômicas ou culturais. Os espaços púbicos são destinados a coletividade, ou seja, de uso 
comum, o qual a população usufrui tanto para atividades rotineiras como periódicas (LIMA, 2006).

É notável o crescimento da população urbana no Brasil, sendo que o percentual chegou a pouco mais de $84 \%$ de acordo com o IBGE no censo de 2010, fenômeno que exige uma organização cada vez maior nas cidades (IBGE, 2010). Pensando no bem-estar dessa população é imprescindível a criação e manutenção de espaços públicos que atendam os anseios da mesma contribuindo para uma melhor qualidade de vida.

Segundo Moro (2003) as praças são locais de encontros e de práticas sociais, onde as manifestações da vida urbana e comunitária são percebidas. Neste contexto Monastirsky (2001) expõe que são nos espaços públicos que ocorrem as relações sociais mais intensas entre os indivíduos, onde se expõe à sociedade, constrói suas relações passando a conhecer e a se reconhecer enquanto cidadão de sua cidade, sendo que esses locais conduzem os indivíduos a uma vida comunitária.

As praças surgiram nas cidades, desde seu princípio como a Ágora e Fórum romano, como um espaço social por excelência, onde ocorriam encontros, tomadas de decisão de interesses da comunidade, espetáculos, execuções, ofícios religiosos, comércios e festas (CALDEIRA, 2007). Com o surgimento de novas alternativas de lazer e de novos locais destinados ao comércio, associado à falta de preocupação com as praças por parte do poder público, esses espaços passaram a se constituírem como um fragmento da malha urbana. A importância dada às praças na atualidade, não condiz com a necessidade crescente dos moradores urbanos (DE ANGELIS, 2000).

Lima et al. (1994) afirmam que as praças estão englobadas dentro da categoria de espaço livre de construção. Os autores conceituam praça como área verde quando arborizada e não impermeabilizada, possuindo função ecológica ou ambiental, estética ou paisagística e de lazer ou recreativa. Guzzo (1999) explica cada uma dessas funções expondo que: a função paisagística está pautada, principalmente, no papel de integração entre o espaço construído e o destinado a circulação; a função recreativa está diretamente ligada à oferta de espaços de lazer para a comunidade; e por fim a função ambiental ocorre quando os elementos naturais minimizam os impactos decorrentes da industrialização.

Pode-se dizer que a categoria de espaço livre se trata de um conceito mais abrangente integrando os demais, contrapondo-se ao espaço construído. Nesse sentido, Santos e Toledo (2008) afirmam que o espaço livre de construção é o espaço destinado ao lazer público e à preservação ou implantação de vegetação, ou seja, da arborização urbana.

Conforme De Angelis e Loboda (2005) os espaços livres enquanto áreas verdes proporcionam inúmeros benefícios tanto para o ambiente urbano como conservar a umidade 
do solo, manter a permeabilidade e fertilidade do solo, entre outros, quanto para a saúde física e mental do homem, quando reduzem a temperatura e poluição além de transmitir um bem-estar psicológico, assim como outros diversos benefícios.

[...] áreas verdes urbanas proporcionam benefícios à população como a proteção contra ventos, a diminuição da poluição sonora, absorção de parte dos raios solares, sombreamento, ambientação à pássaros, absorção da poluição atmosférica, neutralizando os seus efeitos na população (MANTOVI, 2006).

Tanto a arborização urbana quanto os equipamentos destinados ao lazer presente nos espaços livres, sobretudo as praças são responsáveis por proporcionar diversos benefícios tanto para o ambiente quanto ao homem. Conforme Lima et al (1994) a arborização urbana "diz respeito aos elementos vegetais de porte arbóreo, dentro da urbe, [...]. Segundo Benetti e Hilgenberg (2001) a arborização urbana pode ser dívida em arborização privada, restrita às propriedades particulares e em arborização pública, que pode ser subdividida em áreas verdes (praças, jardins, parque, entre outros) e pela arborização das ruas.

Além da arborização as praças devem possuir equipamentos para proporcionar lazer à população, fazendo com que uma das mais importantes funções das praças seja exercida. A infraestrutura das praças é composta por equipamentos, como: bancos, poste de iluminação, lixeira, parques, quadras esportivas, entre outros (DE ANGELIS, 2000).

Em vários trabalhos, como de De Angelis et al. (2004) e Lima (2006) que abordam o tema praças, autores comentam o desinteresse da população em função da deficiência da manutenção e criação desses espaços. Os moradores de menor poder aquisitivo, que justamente por esse motivo não podem frequentar outros locais de convívio social como clubes particulares e "Shoppings Center" são os mais prejudicados, sem a possibilidade de usufruir de locais de entretenimento e lazer, percebendo cada vez mais os problemas da desigualdade social.

O presente trabalho tem como objetivo avaliar a vegetação arbórea e a situação da infraestrutura de 34 praças que estão presentes em oito bairros da cidade de Ponta GrossaPR.

\section{MATERIAIS E MÉTODOS}

Para localizar as praças foi feita uma consulta junto a Prefeitura Municipal de Ponta Grossa para confirmação dos dados levantados em trabalho realizado por Monastirsky 
(2001). Foram selecionadas as praças presentes na área central e em sete bairros contíguos a esta (Figura 1). De um total de 43 praças, trinta e quatro possuíam localização conhecida (Quadro 1) e nove não foram localizadas ou foram descaracterizadas como praças ao serem ocupadas por outras atividades, sendo muitas vezes transformadas em postos de saúde, associação de moradores, entre outros, a exemplo das Praças: Rosevelt Centro; Vitor Contin - Jardim Carvalho; Tereza Cristina - Nova Rússia; José Pedro de Carvalho - Jardim Carvalho; Mal. João Batista M. de Moraes - Jardim Carvalho; Da Música - Olarias; Conrado Schefer - Estrela; Guimarães - Nova Rússia; São Lucas - Centro.

Figura 1. Bairros onde foram realizados os levantamentos qualiquantitativos da vegetação arbórea e infraestrutura das praças em Ponta Grossa-PR

Figure 1. Neighborhoods where there were conducted qualitative and quantitative of individual trees and infrastructure's surveys of the squares in Ponta Grossa-PR

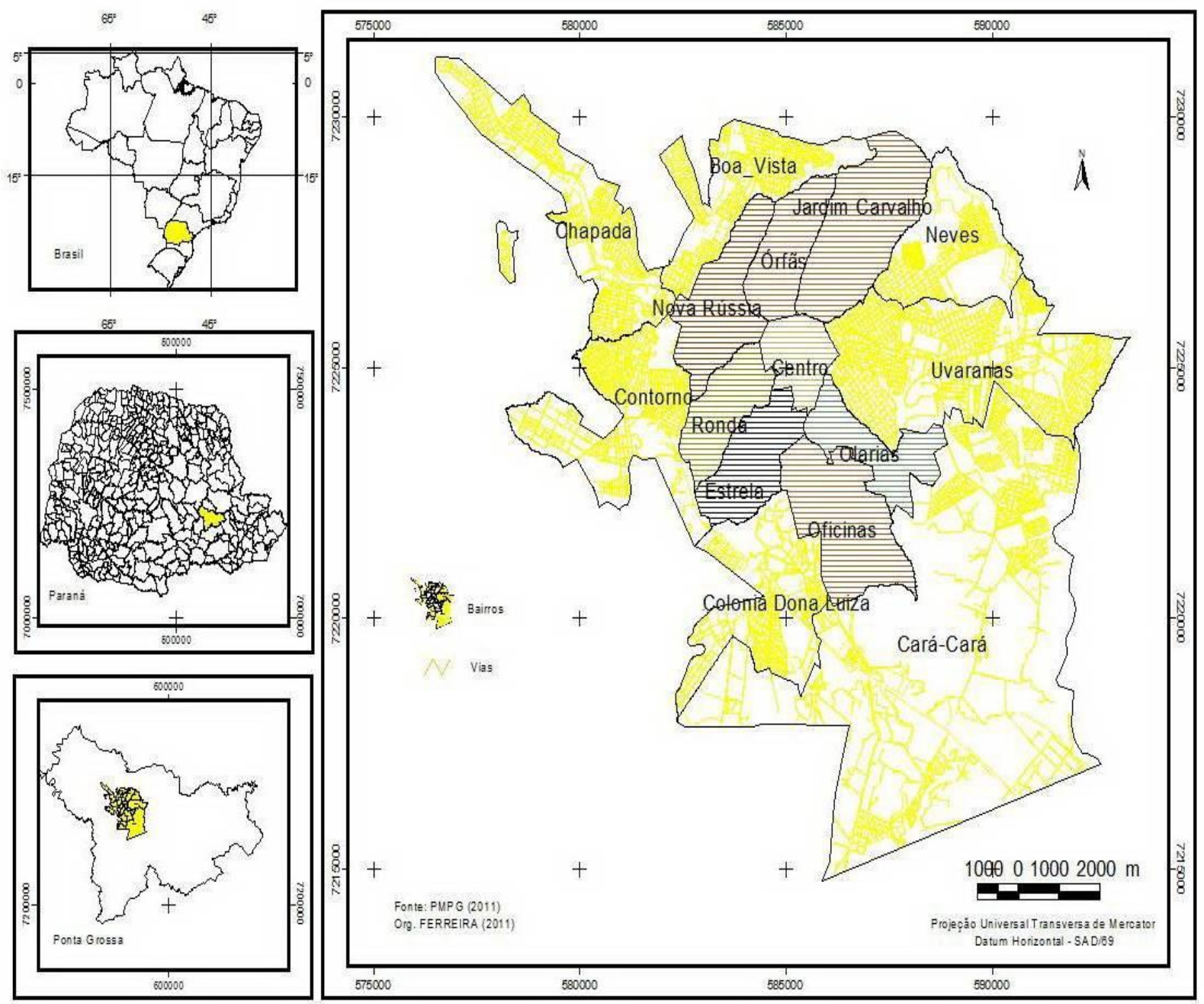

Fonte: PMPG, 2011 / Org: Ferreira, 2011 
Quadro 1. Localização das Praças de Ponta Grossa- PR

Picture 1. Location of Squares of Ponta Grossa-PR

\begin{tabular}{|c|c|c|}
\hline BAIRRO & PRAÇAS & CRUZAMENTO DAS RUAS \\
\hline \multirow[t]{10}{*}{ Centro } & Alfredo Pedro Ribas & Augusto Ribas/ Tibúrcio Ferreira \\
\hline & Barão do Guaraúna & Paula Xavier/ Av. Vicente Machado \\
\hline & Barão do Rio Branco & Bonifácio Vilela/ Rosário \\
\hline & $\begin{array}{l}\text { Parque Ambiental Gov. Manoel } \\
\text { Ribas }\end{array}$ & Benjamim Constant/ Av. Vicente Machado \\
\hline & Do Expedicionário & Rosário/ Av. Vicente Machado \\
\hline & Duque de Caxias & Rosário/ Catão Monclaro \\
\hline & João Pessoa & Av. Fernandes Pinheiro \\
\hline & Mal. Floriano Peixoto & Santana \\
\hline & Prof. Colares & Júlio de Castilhos/ Av. Ernesto Vilela \\
\hline & Santos Andrade & Júlio de Castilho/ Av. Bonifácio Vilela \\
\hline \multirow[t]{3}{*}{ Estrela } & Ângelo Moro & Silvia M. de Souza/ Benedito L. Bragania \\
\hline & Clube Serra de Ponta Grossa & Dro Joaquim de Paula Xavier/ Freire Alemão \\
\hline & Margarida Malucelli Moro & Afonso Pena/ Joaquim de Paula Xavier \\
\hline \multirow{4}{*}{$\begin{array}{l}\text { Jardim } \\
\text { Carvalho }\end{array}$} & Bispo Antônio Mazzaroto & Otávio de Carvalho/ Bernardo Vasconcelos \\
\hline & Rotary Internacional & Saldanha da Gama/ Av. Monteiro Lobato \\
\hline & Dos Aposentados & Catão Monclaro/ Alfonso Celso \\
\hline & João Maria Cordeiro & Barão do Cerro Azul/ Catão Monclaro \\
\hline \multirow{4}{*}{$\begin{array}{l}\text { Nova } \\
\text { Rússia }\end{array}$} & Cidade de Curitiba & Osmário Ribas/ Av.Dom Pedro II \\
\hline & Dom Pedro II & Osmário Ribas/Av. Dom Pedro II \\
\hline & Getúlio Vargas & Av. Ernesto Vilela/ Maurício de Nassal \\
\hline & Prof. Álvaro Holzmann & Francisco Otaviano/ Jaguapitã \\
\hline \multirow[t]{7}{*}{ Oficinas } & Frei Elias Zulian & João Frare/ João Dubois \\
\hline & Guairacá & Carlos de Laet \\
\hline & Igreja Luterana & Emílio de Menezes/ Av. Visconde de Mauá \\
\hline & Isidoro Ferrer Alfaro & Lapa/ Thaumaturgo de Azevedo \\
\hline & João Montes Filho & Artur de Azevedo/ Freire Alemão \\
\hline & Madre Maria dos Anjos & Dr Paula Xavier/ Av. Visconde de Mauá \\
\hline & Simão Bolívar & Dom Pedro l/ Av. Visconde de Mauá \\
\hline Olarias & Pedro Ribas & Oliveira Martins/ Operários \\
\hline \multirow[t]{3}{*}{ Órfãs } & Ana Batista Miró Guimarães & Júlia Lopez/ Herculano de Freitas \\
\hline & São José & Princesa Isabel/ Rocha Carvalhais \\
\hline & Lourival dos Santos Lima & Prof. Sinara N. de Paula/ Rio Grande do Sul \\
\hline \multirow[t]{2}{*}{ Ronda } & Cel. Cristiano Justus Júnior & Cardoso Fontes/ Alm. Tamandaré \\
\hline & Hulda Roedel & Baltazar Lisboa/ Colômbia \\
\hline
\end{tabular}

Considerando a estrutura física das praças, foram analisados quali-quantitativamente os elementos presentes nas mesmas, ou seja, a arborização e os equipamentos que 
compõe a infraestrutura, a fim de avaliar esses espaços importantes dentro do cenário urbano.

Com relação à avaliação da vegetação arbórea, a mesma foi analisada quantitativamente, utilizando uma ficha de campo na qual constava o nome da Praça, a localização (bairro ou vila e o cruzamento das principais ruas), o nome do avaliador e a data. Consta ainda o nome popular e científico da(s) espécie(s) arbórea(s) presente(s), a família, a origem, se a espécie é nativa ou exótica e a quantidade de indivíduos encontrados. Quanto à origem das espécies, as nativas são as espécies originárias de formações vegetais ocorrentes no Brasil e as espécies que ocorrem em outros ecossistemas diferentes dos que aparecem em território brasileiro, são consideradas exóticas. A identificação foi feita com todos os indivíduos arbóreos, sem utilizar critérios de censura para os indivíduos arbóreos mais jovens. A identificação foi realizada in loco com a ajuda do manual de identificação e cultivo de plantas arbóreas (LORENZI, 1998a; 1998b; LORENZI et al., 2003) e por meio de coleta de material botânico, quando da impossibilidade de identificação no local, sendo levados para o herbário da Universidade Estadual de Ponta Grossa, para posterior identificação.

$\mathrm{Na}$ análise qualitativa dos indivíduos arbóreos foram verificados o porte e os aspectos físicos de cada árvore. Para analisar o porte foi utilizada a metodologia de Santos e Teixeira (2001), onde foi considerado:

- Muda - vegetal com até $1 \mathrm{~m}$ de altura;

- Pequeno porte - vegetal com altura entre $1,01 \mathrm{~m}$ e $3 \mathrm{~m}$;

- Médio porte - vegetal com altura entre $3 \mathrm{~m}$ e $6 \mathrm{~m}$ e

- Grande porte - vegetal com mais de $6 \mathrm{~m}$.

Para a análise dos aspectos físicos que avalia as injúrias mecânicas foi utilizada a metodologia aplicada por Santos e Teixeira (1991):

- Boa - isenta de sinais de injúrias mecânicas, ou seja, não apresenta podas. Apresenta forma característica da espécie.

- Satisfatória - apresenta pequenos danos físicos, sendo podas incorretas e/ou desnecessárias. Necessita de poda corretiva, para garantir a forma característica ou arquitetônica das espécies ou para eliminar galhos baixos que dificultam a passagem de pedestres e de veículos.

Ruim - apresenta severos danos físicos, ou seja, inúmeras podas incorretas e/ou desnecessárias, além de doenças. Requer muito trabalho para recuperação, sendo necessário acompanhamento para verificar como está o crescimento, realizando podas corretivas para que se preserve a forma característica da espécie e controle da doença. 
- Morta - ou que apresente morte iminente por doenças ou por podas radicas realizadas muito próximas as raízes das árvores.

Buscando compreender não somente a estrutura física, mas também a praça enquanto espaço ocupado pelo homem para diversos usos e funções optou-se em realizar uma análise tanto quantitativa quanto qualitativa em toda a infraestrutura que compões as praças. Utilizou-se a metodologia de De Angelis (2000) que consiste em dois formulários a serem preenchidos a campo.

No primeiro formulário, foi feita à análise quantitativa, que busca levantar a existência ou não de equipamentos e a quantidade. São ao todo vinte e dois itens a serem verificados, além da opção outros que pode ser especificada na observação do formulário. A escolha dos equipamentos que compõe o formulário foi feita a partir da análise dos equipamentos mais comuns presentes nas praças.

No segundo formulário, avaliou-se o aspecto qualitativo. Foi verificado o estado da conservação dos equipamentos e a estrutura, atribuindo uma nota que varia de 0 a 4 , podendo o equipamento ou a estrutura ser de:

- 0 a 1,0 - péssimo: sem condições de uso;

- 1,0 a 2,0 - regular: estruturas comprometidas, muitas vezes por atos de vandalismo ou em más condições devido ao tempo de uso;

- 2,0 a 3,0 - bom: estruturas confeccionadas em matérias resistentes como concreto e ferro ou em madeira com longa durabilidade, bem conservados, ou seja, sem depredações;

- 3,0 a 4,0 ótimo: além de serem confeccionados em material resiste e livre de depredações, os equipamentos se encontram bem distribuídos pela praça, sem rejeição por parte dos usuários.

Assim, para atribuir a nota aos equipamentos foi levando em consideração o estado de conservação (relacionado a depredação), o material empregado na confecção, a localização dentro da praça e a rejeição por parte dos usuários. Para as estruturas foram considerados sua manutenção, a situação que se encontram o conforto e a utilização das praças. Os parâmetros observados e usados para atribuir a nota foram os mesmos propostos por De Angelis (2000):

- Bancos: estado de conservação; material empregado em sua confecção; conforto; locação ao longo dos caminhos - se recuados ou não; distribuição espacial - se em áreas sombreadas ou não; desenho; quantidade; distanciamento. 
- Iluminação: alta ou baixa - em função da copa das árvores; tipo - poste, super poste, baliza, holofote; localização; conservação; atendimento ao objetivo (se realmente ilumina o espaço).

- Lixeiras: tipo; quantidade; localização; funcionalidade (se há condições de uso, ligado a conservação); material empregado; distanciamento.

- Sanitários: condições de uso (se a estrutura tem condições de atender a população, relacionada com a conservação, ou seja, a depredação e o tempo de uso) e quantidade.

- Telefone público: localização - na praça, próximo ou distante de; conservação.

- Bebedouros: tipo; quantidade; condições de uso e conservação.

- Piso: material empregado; funcionalidade (se há condições de uso, ligado a conservação) e segurança.

- Traçado dos caminhos: funcionalidade; largura; manutenção (se há manutenção por parte o poder público); desenho (se há caminhos suficientes dando acesso a todas as estruturas da praça).

- Palco/coreto: funcionalidade; conservação; design; uso - frequente, esporádico, sem uso; se compatível com o desenho da praça.

- Monumento, estátua, busto: significância da obra de arte (se há relação com a praça e/ou não compromete o design, se não compromete no conjunto da praça); conservação.

- Espelho d'água/chafariz: em funcionamento; se inserido ou não no contexto da praça (se não se encontra isolado, prejudicando o conjunto da praça); conservação.

- Estacionamento: conservação; sombreamento; segurança.

- Ponto de ônibus e de táxi: se na praça, próximo ou distante de; presença ou não de abrigo; conservação.

- Quadra esportiva: quantidade; conservação; material empregado; com iluminação; cercada.

- Equipamentos para prática de exercícios físicos: tipo e quantidade; material empregado; conservação.

- Estrutura para terceira idade: estruturas existentes; conservação.

- Parque infantil: brinquedos que o compõem; material empregado e cor; se em área reservada e protegida; conservação.

- Banca de revista: localização - periférica ou central; material empregado em sua construção; se compatível com a praça. 
- Quiosque para alimentação e/ou similar: tipo - trailer, carrinho, construção em alvenaria; higiene; estética (ligado com a conservação da estrutura); localização.

- Segurança: em função da localização, frequência de pessoas, policiamento e conservação.

- Conservação geral: estado geral da praça - equipamentos, estruturas, varrição, limpeza.

- Localização: se próximo ou distante de centros habitados; facilidade de acesso.

- Vegetação: quantidade e manutenção (necessidade ou não de podas).

- Paisagismo: escolha e locação das diferentes espécies; inserção do verde no conjunto sem comprometer a utilização das estruturas existentes nas praças.

- Elementos que podem afetar o Conforto acústico: presença de agentes causadores de barulho.

- Fatores que podem afetar o Conforto térmico: relação entre área sombreada e não; impermeabilização da área da praça e seu conjunto.

- Fatores que podem afetar o Conforto visual: harmonia entre elementos construídos e vegetação (se a vegetação não cobre elementos arquitetônicos como monumentos e se equipamentos impedem o crescimento da vegetação), característica visual do entorno (se os elementos arquitetônicos e a vegetação condizem com o entorno da praça).

Após a atribuição de nota para cada equipamento e estrutura efetuou-se uma média aritmética simples, obtendo uma nota final e um conceito (ótimo, bom, regular ou péssimo) que possibilitou classificar o estado de conservação de cada equipamento.

\section{RESULTADOS E DISCUSSÕES}

Foram analisados 1.467 indivíduos arbóreos presentes nas trinta e quatro praças, compostos por 63 espécies e 33 famílias conforme demonstrado na tabela 1. Do total de indivíduos arbóreos analisados, 24 não puderam ser identificados em função de podas radicais ou pela ausência de flores ou frutos.

Dentre as espécies 64,1\% (925 indivíduos arbóreos) são exóticas e 35,8\% (518 indivíduos arbóreos) são nativas. São frequentes, na bibliografia consultada, trabalhos que apresentam um maior percentual de espécies exóticas, como a pesquisa desenvolvida por Bohner et al. (2011) para as praças do município de Guatambu (SC) onde o predomínio das espécies exóticas alcançou 76,25\% e Santos e Rezende (2010) também constatou um 
percentual maior de espécies exóticas $(63,73 \%)$ em sua pesquisa no bairro de Jaraguá em Uberlândia-MG.

Tabela 1. Espécies catalogadas em trinta e quatro praças de Ponta Grossa-PR

Table 1. Species cataloged in thirty-four squares of Ponta Grossa-PR

\begin{tabular}{|c|c|c|c|c|c|}
\hline Família & Nome popular & Nome científico & Origem & $\begin{array}{l}\text { Quanti } \\
\text { dade }\end{array}$ & $\begin{array}{c}\text { Frequê } \\
\text { ncia } \\
(\%)\end{array}$ \\
\hline Aceraceae & Ácer-roxo & Acer palmatum & Exótica & 14 & 1,0 \\
\hline \multirow[t]{2}{*}{ Agavaceae } & luca-elefante & Yucca elephantipes & Exótica & 18 & 1,2 \\
\hline & Dracena-azul & Cordyline australis & Exótica & 3 & 0,2 \\
\hline \multirow[t]{2}{*}{ Anacardiaceae } & Aroeira & Myracrodruon urundeuva & Nativa & 22 & 1,5 \\
\hline & Aroeira-salsa & Schinus molle & Nativa & 2 & 0,1 \\
\hline Annonaceae & Araticum-roxo & Annona coriácea & Nativa & 4 & 0,3 \\
\hline \multirow[t]{2}{*}{ Apocynaceae } & Espirradeira & Nerium oleander & Exótica & 7 & 0,5 \\
\hline & Alstônia & Alstonia macrophylla & Exótica & 1 & 0,1 \\
\hline Aquifoliaceae & Erva-mate & Ilex paraguariensis & Nativa & 1 & 0,1 \\
\hline Araliaceae & Pata-de-ganso & Trevesia palmata & Exótica & 1 & 0,1 \\
\hline Araucariaceae & Pinheiro-do-Paraná & Araucaria angustifolia & Nativa & 28 & 1,9 \\
\hline \multirow{3}{*}{ Arecaceae } & Jerivá & Syagrus romanzoffiana & Nativa & 150 & 10,2 \\
\hline & Carnaubeira & Copernicia prunifera & Nativa & 30 & 2 \\
\hline & Butiá & Butia eriospatha & Nativa & 3 & 0,2 \\
\hline \multirow{5}{*}{ Bignoniaceae } & Jacarandá-mimoso & Jacaranda mimosifolia & Exótica & 87 & 5,9 \\
\hline & Ipê-amarelo & Handroanthus alba & Nativa & 68 & 4,6 \\
\hline & Bisnagueira & Spathodea nilotica & Exótica & 25 & 1,7 \\
\hline & Ipê-roxo & Handroanthus impetiginosa & Nativa & 11 & 0,7 \\
\hline & Amarelinho & Tecoma stans & Exótica & 7 & 0,5 \\
\hline Bombacaceae & Paineira-rosa & Ceiba speciosa & Nativa & 45 & 3,1 \\
\hline Cunoniaceae & Açoita-cavalo & Lamanonia ternata & Nativa & 1 & 0,1 \\
\hline \multirow{3}{*}{ Cupressaceae } & Cedrinho & Cupressus Iusitanica & Exótica & 46 & 3,1 \\
\hline & Tuia-macarrão & Chamaecyparis pisifera & Exótica & 2 & 0,1 \\
\hline & Cipestre-Grisalho & Juniperus chinensis & Exótica & 1 & 0,1 \\
\hline Euphorbiaceae & Leiteiro-vermelho & Euphorbia cotinifolia & Exótica & 3 & 0,2 \\
\hline \multirow{11}{*}{ Fabaceae } & Pata-de-vaca & Bauhinia variegata & Exótica & 35 & 2,4 \\
\hline & Mulungo-do-litoral & Erythrina speciosa & Nativa & 20 & 1,4 \\
\hline & Cássia-imperial & Cassia fistula & Exótica & 16 & 1,1 \\
\hline & Guapuruvu & Schizolobium parahyba & Nativa & 11 & 0,7 \\
\hline & Carvalho & Quercus robur & Exótica & 3 & 0,2 \\
\hline & Ángico & Anadenanthera macrocarpa & Nativa & 29 & 2 \\
\hline & Tipuana & Tipuana tipu & Exótica & 66 & 4,5 \\
\hline & Manduírana & Senna macranthera & Nativa & 4 & 0,3 \\
\hline & Acácia mimosa & Acacia podalyraefolia & Exótica & 50 & 3,4 \\
\hline & Leucena & Leucaena leucocephala & Exótica & 8 & 0,5 \\
\hline & Albízia & Albizia falcataria & Exótica & 5 & 0,3 \\
\hline \multirow[t]{2}{*}{ Lythraceae } & Extremosa & Lagerstroemia indica & Exótica & 56 & 3,8 \\
\hline & Romã & Punica granatum & Exótica & 8 & 0,5 \\
\hline Magnoliaceae & Magnólia-branca & Magnolia grandiflora & Exótica & 3 & 0,2 \\
\hline Melastomaceae & Manacá-da-serra & Tibouchina mutabilis & Nativa & 35 & 2,4 \\
\hline Meliaceae & Cinamomo & Melia azedarach & Exótica & 20 & 1,4 \\
\hline \multirow{3}{*}{ Moraceae } & Figueira-branca & Ficus guaranitica & Nativa & 21 & 1,4 \\
\hline & Ficus-benjamina & Ficus benjamina & Exótica & 10 & 0,7 \\
\hline & Seringueira & Ficus elástica & Exótica & 6 & 0,4 \\
\hline
\end{tabular}




\begin{tabular}{l|l|l|l|r|r}
\hline & Amora-preta & Morus nigra & Exótica & 3 & 0,2 \\
\hline \multirow{4}{*}{ Myrtaceae } & Eucalipto-azul & Eucalyptus cinerea & Exótica & 15 & 1 \\
\cline { 2 - 6 } & Pitanga & Eugenia uniflora & Nativa & 9 & 0,6 \\
\cline { 2 - 6 } & Goiaba-branca & Psidium guajava & Nativa & 4 & 0,3 \\
\cline { 2 - 6 } & Araçá & Psidium cattleianum & Nativa & 3 & 0,2 \\
\cline { 2 - 6 } & Eucalipto & Eucalyptus pilularis & Exótica & 2 & 0,1 \\
\cline { 2 - 6 } & Cereja & Eugenia involucrata & Nativa & 1 & 0,1 \\
\hline Nyctaginaceae & Primavera-arbórea & Bougainvillea glabra & Nativa & 7 & 0,5 \\
\hline Pleaceae & Ligustro & Ligustrum lucidum & Exótica & 287 & 19,6 \\
\hline \multirow{2}{*}{ Proteaceae } & Pinus & Pinus echinata & Exótica & 2 & 0,1 \\
\hline \multirow{2}{*}{ Rosaceae } & Grevilha & Grevillea robusta & Exótica & 16 & 1,1 \\
\hline \multirow{2}{*}{ Salicaceae } & Piracanta & Pyracantha coccinea & Exótica & 65 & 4,4 \\
\cline { 2 - 6 } & Ameixeira & Eriobotrya japonica & Nativa & 3 & 0,2 \\
\cline { 2 - 6 } & Pessegueiro-bravo & Prunus myrtifolia & Nativa & 2 & 0,1 \\
\hline \multirow{2}{*}{ Taxodiaceae } & Jenipapeiro & Genipa americana & Nativa & 4 & 0,3 \\
\hline & Allamo & Populus deltoides & Exótica & 9 & 0,6 \\
\cline { 2 - 6 } & Chorão-ereto & Salix nigra & Exótica & 2 & 0,1 \\
\hline TOTAL & Pinheiro-chinês & Cunninghamia lanceolata & Exótica & 22 & 1,5 \\
\cline { 2 - 6 } & Cedro-japônes & Cryptomeria japonica & Exótica & 1 & 0,1 \\
\cline { 2 - 6 } & Não identificadas & & & 24 & 1,6 \\
\hline
\end{tabular}

Segundo Milano e Dalcin (2000) uma mesma espécie não deve ultrapassar 15\% do total de indivíduos arbóreos. Nesse levantamento foi constatado que apenas o Ligustrum lucidum (Ligustro) ultrapassa esse valor com 19,6\% conforme demonstrado na tabela 1.

Das 34 praças analisadas, três delas não possuem nenhum indivíduo arbóreo, são elas: Ana Batista Miró Guimarães, dos Aposentados e Lourival dos Santos Lima. No Parque Ambiental Gov. Manuel Ribas foi encontrado o maior número de árvores, sendo contabilizadas 529 , que representam $35,4 \%$ do total de espécies encontradas. A praça com menor número de árvores foi a Praça Pedro Ribas em Olarias com apenas duas árvores da mesma espécie, Melia azedarach (Cinamomo).

Dez espécies foram responsáveis por $62,7 \%$ dos indivíduos arbóreos levantados. Por haver 64 espécies diferentes e dez delas já ultrapassarem 50\%, mostra que muitas espécies são pouco representativas. Várias espécies possuem apenas um representante nas 35 praças, o que não contribui para a biodiversidade regional.

No levantamento do porte dos indivíduos arbóreos (Tabela 2) predominaram as espécies de grande porte, com $66,2 \%$ do total analisado. As espécies com maior frequência dentro dessa classe foram: Ligustrum lucidum (24,3\%), Syagrus romanzoffiana $(13,7 \%)$ e Jacaranda mimosifolia (8,9\%). As mudas apresentaram baixo índice, apenas 2,1\%, mostrando que não está ocorrendo plantio de espécies nas praças, comprovando a necessidade de um Plano de Arborização Urbana.

Quanto ao levantamento dos aspectos físicos, também exposto na Tabela 2, a maioria dos indivíduos arbóreos apresenta-se em bom estado de conservação, ou seja 
preservaram a forma característica da espécie, com 1.014 indivíduos dentro dessa classe, representando 69,1\%, com destaque para o Ligustrum lucidum (Ligustro) com 19,3\%, Syagrus romanzoffiana (Jerivá) com 14,6\% e Jacaranda mimosifolia (Jacarandá-mimoso) com 5,9\%.

Foram observadas poucas podas, possivelmente porque as praças são consideradas como locais estratégicos para o plantio de árvores, não necessitando de podas por conflitos (com rede elétrica ou calçadas, por exemplo), porém necessitam de podas corretivas, pois muitas foram plantadas e esquecidas.

Tabela 2. Levantamento qualitativo dos indivíduos arbóreos em trinta e quatro praças em Ponta Grossa-PR

Table 2. Qualitative survey of individual trees in thirty-four squares in Ponta Grossa-PR

\begin{tabular}{|c|c|c|c|c|c|c|c|c|c|}
\hline \multirow[t]{2}{*}{ NOME POPULAR } & \multirow[t]{2}{*}{ NOME CIENTÍFICO } & \multicolumn{4}{|c|}{$\begin{array}{c}\text { PORTE } \\
\text { ARBÓREO/QUANTIDADE* }\end{array}$} & \multicolumn{4}{|c|}{$\begin{array}{l}\text { ASPECTOS FíSICOS - } \\
\text { QUANTIDADE** }^{\star *}\end{array}$} \\
\hline & & $\mathbf{M}$ & $\mathbf{P}$ & Mé & $\mathbf{G}$ & B & $\mathbf{S}$ & $\mathbf{R}$ & Mo \\
\hline Acácia-mimosa & Acacia podalyraefolia & & & 50 & & 50 & & & \\
\hline Ácer-japonês & Acer palmatum & & & 2 & 2 & 1 & 3 & & \\
\hline Ácer-roxo & Acer palmatum & & 2 & 3 & 5 & 9 & 1 & & \\
\hline Açoita-cavalos & Lamanonia ternata & & & 1 & & 1 & & & \\
\hline Álamo & Populus deltoides & & & & 9 & & 9 & & \\
\hline Albízia & Albizia falcataria & & & & 5 & 4 & 1 & & \\
\hline Alstônia & Alstonia macroplylla & & & & 1 & & 1 & & \\
\hline Ameixeira & Eriobotrya japonica & & & & 3 & & 3 & & \\
\hline Amora-preta & Morus nigra & & 2 & 1 & & 2 & 1 & & \\
\hline Angico & Anadenanthera macrocarpa & & 1 & 4 & 24 & 3 & 26 & & \\
\hline Araçá & Psidium cattleianum & 2 & & 1 & & & 3 & & \\
\hline Araticum-roxo & Annona coriacea & & & & 4 & 4 & & & \\
\hline Aroeira & Myracrodruon urundeuva & 1 & 1 & 8 & 12 & 14 & 8 & & \\
\hline Aroeira-salsa & Schinus molle & & & & 2 & 2 & & & \\
\hline Bignonia-amarela & Tecoma stans & & 7 & & & & 7 & & \\
\hline Bisnagueira & Spathodea nilotica & & & 7 & 18 & 21 & 4 & & \\
\hline Butiá & Butia eriospatha & & & 3 & & 3 & & & \\
\hline Carnaubeira & Copernicia prunifera & 1 & 19 & 7 & 3 & 28 & 2 & & \\
\hline Carvalho & Quercus robur & & & & 3 & 3 & & & \\
\hline Cássia-imperial & Cassia fistula & & & 3 & 13 & 9 & 7 & & \\
\hline Cedro & Cupressus lusitanica & & 3 & 9 & 34 & 33 & 10 & 3 & \\
\hline Cedro-japônes & Cryptomeria japonica & & & & 1 & 1 & & & \\
\hline Cereja & Eugenia involucrata & & 1 & & & & 1 & & \\
\hline Chorão-ereto & Salix nigra & & & & 2 & 2 & & & \\
\hline Cinamomo & Melia azedarach & & & 2 & 18 & 11 & 9 & & \\
\hline Cipestre-grisalho & Junipeirus chinensis & & & 1 & & 1 & & & \\
\hline Dracena-azul & Cordyline australis & & & 3 & & 3 & & & \\
\hline Erva-mate & Ilex paraguariensis & & 1 & & & & 1 & & \\
\hline Espirradeira & Nerium oleander & & 5 & 2 & & & 7 & & \\
\hline Eucalipto & Eucalyptus pilularis & & & & 2 & 2 & & & \\
\hline
\end{tabular}




\begin{tabular}{|c|c|c|c|c|c|c|c|c|c|}
\hline Eucalipto-azul & Eucalyptus cinerea & & & & 15 & 15 & & & \\
\hline Extremosa & Lagerstroemia indica & & & 38 & 18 & 50 & 6 & & \\
\hline Ficus-benjamina & Ficus benjamina & & 4 & & 6 & 3 & 7 & & \\
\hline Figueira-branca & Ficus guaranitica & & 2 & 13 & 6 & 18 & 3 & & \\
\hline Goiaba-branca & Psidium guajava & & 2 & 1 & 1 & 3 & 1 & & \\
\hline Grevilha & Grevillea robusta & & & & 16 & 14 & 2 & & \\
\hline Guapuruvu & Schizolobium parahyba & & 4 & 1 & 6 & 8 & 3 & & \\
\hline Ipê-amarelo & Handroanthus alba & & 4 & 8 & 56 & 41 & 27 & & \\
\hline Ipê-roxo & Handroanthus impetiginosa & & 1 & 5 & 5 & 8 & 3 & & \\
\hline luca-elefante & Yucca elephantipes & 1 & & 7 & 10 & 15 & 3 & & \\
\hline Jacarandá-mimoso & Jacaranda mimosifolia & & & 1 & 86 & 60 & 27 & & \\
\hline Jenipapeiro & Genipa americana & & & & 4 & 2 & 2 & & \\
\hline Jerivá & Syagrus romanzoffiana & & 3 & 15 & 132 & 148 & 2 & & \\
\hline Leiteiro-vermelho & Euphorbia cotinifolia & & & 2 & 1 & 1 & 2 & & \\
\hline Leucena & Leucaena leucocephala & 1 & & 2 & 5 & 2 & 6 & & \\
\hline Ligustro & Ligustrum lucidum & 10 & 4 & 39 & 234 & 196 & 85 & & 6 \\
\hline Magnólia & Magnolia grandiflora & & & 2 & 1 & 3 & & & \\
\hline Manacá-da-serra & Tibouchina mutabilis & & 2 & 11 & 22 & 12 & 23 & & \\
\hline Manduirana & Senna macranthera & & & & 4 & 2 & 2 & & \\
\hline Mulungo-do-litoral & Erythrina speciosa & & & 20 & & 16 & 4 & & \\
\hline Paineira-rosa & Ceiba speciosa & & 1 & 4 & 40 & 4 & 5 & 15 & \\
\hline Pata-de-ganso & Trevesia palmata & & & & 1 & 43 & 2 & & \\
\hline Pata-de-vaca & Bauhinia variegata & & 1 & 15 & 19 & 1 & & & \\
\hline Pessegueiro-bravo & Prunus myrtifolia & & 1 & 1 & & 13 & 22 & & \\
\hline Pinheiro-chinês & Cunninghamia lanceolata & 1 & & & 21 & 2 & & & \\
\hline Pinheiro-do- Paraná & Araucaria angustifolia & 7 & 4 & 4 & 13 & 21 & 1 & & \\
\hline Pinus & Pinus echinata & & & & 2 & 28 & & & \\
\hline Piracanta & Pyracantha coccinea & 3 & 6 & 52 & 4 & 2 & & & \\
\hline Pitanga & Eugenia uniflora & 3 & 4 & 2 & & 5 & 60 & & \\
\hline Primavera-arbórea & Bougainvillea glabra & & & & 7 & 3 & 6 & & \\
\hline Romã & Punica granatum & & 8 & & & 1 & 6 & & \\
\hline Seringueira & Ficus elástica & & & & 6 & 6 & 2 & & \\
\hline Tipuana & Tipuana tipu & & & 8 & 58 & 6 & & & \\
\hline Tuia-macarrão & Chamaecyparis pisifera & & 2 & & & 53 & 11 & & 2 \\
\hline Não identificadas & & & 4 & 4 & 1 & 2 & & & \\
\hline \multirow{2}{*}{ TOTAL } & Quantidade & 30 & 99 & 362 & 961 & 1014 & 427 & 18 & 8 \\
\hline & Frequência \% & 2,1 & 6,8 & 25 & 66,2 & 69,1 & 29,1 & 1,2 & 0,5 \\
\hline
\end{tabular}

* M Muda; P Pequeno; Mé Médio; G Grande

** B Boa; S Satisfatória; R Regular; Mo Morta

No levantamento quantitativo da infraestrutura (Figura 2) verificou-se que a estrutura mais frequente foram os caminhos presentes em 29 praças do total de 34, representando 85,2\%. Harder (2002) ao analisar as praças na cidade de Vinhedo em São Paulo, também constatou que os caminhos são as estruturas mais frequentes com $81,81 \%$.

Após os caminhos as estruturas mais frequentes foram: iluminação $(79,4 \%)$, bancos (73,5\%), telefones públicos (47,0\%), monumentos e identificação, ambos com $41,1 \%$. As demais estruturas não chegaram a estar presentes em $40 \%$ das praças. As estruturas 
menos frequentes foram os templos religiosos e os espelhos d'água presentes em apenas uma das praças. O bebedouro foi único equipamento ausente.

Lima et al. (1994) afirma que a principal função da praça é o lazer, seja o lazer passivo ou ativo, assim, há elementos básicos para que as praças proporcionem tal função. Consideram-se então como esses elementos, os bancos, iluminação e caminhos. Mesmo estes sendo os itens mais frequentes não são todas as praças que possuem essas estruturas, denotando uma carência no planejamento.

Observa-se que as praças mais equipadas estão localizadas no centro da cidade. $\mathrm{O}$ bairro Olarias foi o que apresentou maiores deficiências, pois há apenas uma praça e a mesma não possui nenhum equipamento. O cenário sobre a infraestrutura é bem heterogêneo, em função de que há praças dotadas de uma grande infraestrutura e outras não apresentam nenhum equipamento.

Das trinta e quatro praças analisadas vinte e sete possuem iluminação e vinte cinco possuem bancos, são elementos básicos, porém não estão presentes em todas as praças.

Quanto ao levantamento qualitativo realizado na infraestrutura das praças (Figura 3) apenas dois itens receberam conceito ótimo, que foram os equipamentos para exercícios físicos e a localização das praças. Todas as praças estão localizadas próximo aos centros habitados e a grande maioria tem fácil acesso. A maior parte dos itens está em bom estado de conservação, ou seja, a maioria dos equipamentos não se encontram depredados e foram construídos com ferro e concreto, matérias mais resistentes. Onze estruturas receberam o conceito de regular, o ideal seria que as mesmas recebessem no mínimo o conceito bom, para que a população pudesse usufruir desses espaços.

Vale ressaltar que os equipamentos receberam números fracionados em função dos diversos atributos considerados para a avaliação. A quantidade foi o atributo que mais atribuía valores fracionados. 
Figura 2. Avaliação quantitativa dos equipamentos e estruturas de 34 praças de Ponta Grossa-PR

Figure 2. Quantitative evaluation of equipment and structures of 34 squares of Ponta Grossa-PR

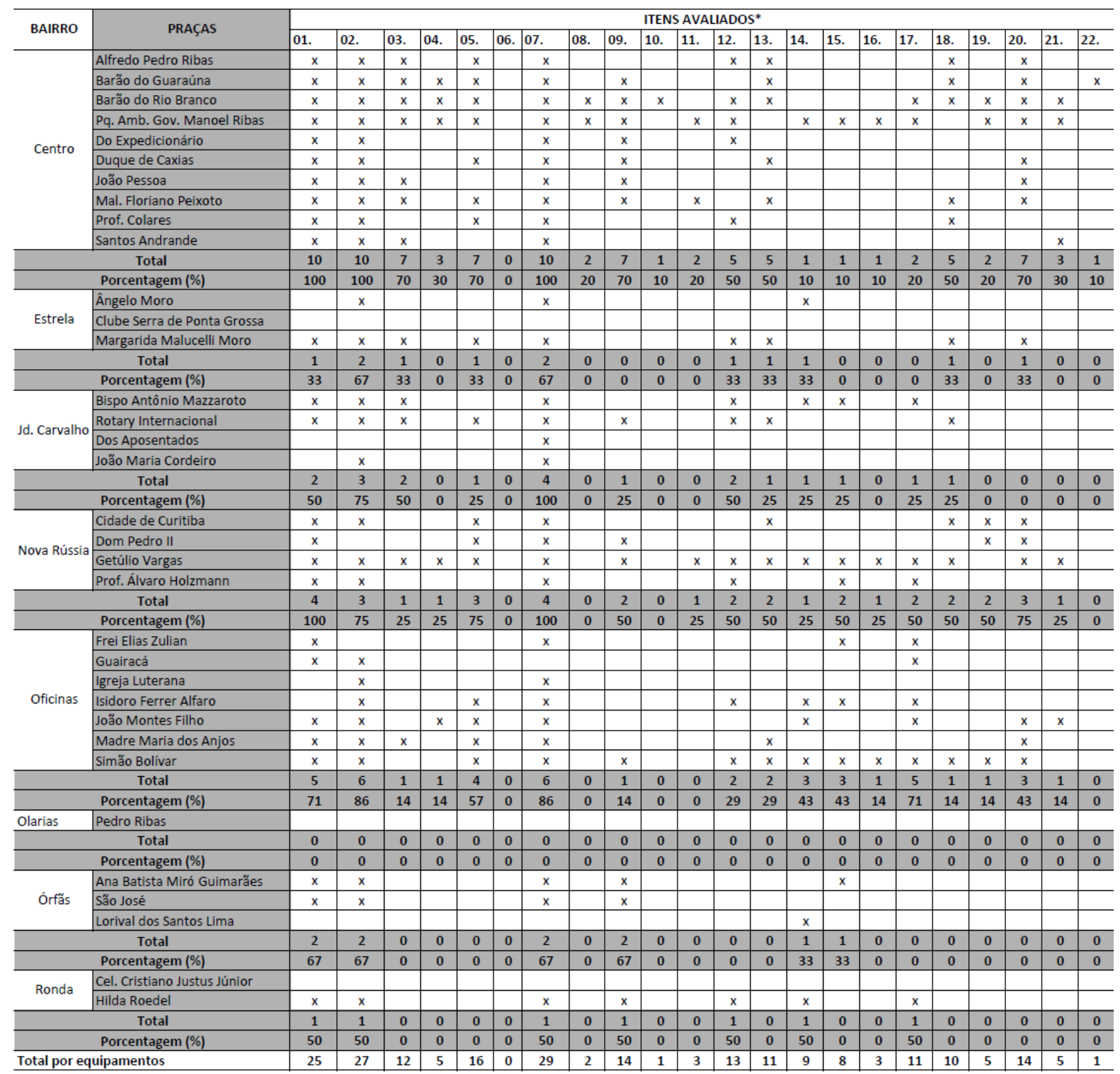

* 01 Bancos; 02 Iluminação; 03 Lixeiras; 04 Sanitários; 05 Telefone público; 06 Bebedouros; 07 Caminhos; 08 Palco/coreto; 09 Monumento, estátua, busto; 10 Espelho d’água/chafariz; 11 Estacionamento; 12 Ponto de ônibus; 13 Ponto de táxi; 14 Quadra esportiva; 15 Para prática de exercícios físicos; 16 Para terceira idade; 17 Parque infantil; 18 Banca de revista; 19 Quiosque de alimentação ou similar; 20 Identificação; 21 Edificação institucional; 22 Templo religioso. 
Figura 3. Avaliação qualitativa dos equipamentos e estruturas de 34 praças de Ponta Grossa-PR

Figure 3. Qualitative assessment of equipment and structures of 34 squares of Ponta Grossa-PR

\begin{tabular}{|c|c|c|c|c|c|c|c|c|c|c|c|c|c|c|c|c|c|c|c|c|c|c|c|c|c|c|c|c|c|}
\hline \multirow{2}{*}{ BARRO } & \multirow{2}{*}{ PRAÇAS } & \multicolumn{28}{|c|}{ ITENS AVALIADOS ${ }^{\star}$} \\
\hline & & 01. & \begin{tabular}{|l|}
02. \\
\end{tabular} & \begin{tabular}{|l|l|}
03. & 0 \\
\end{tabular} & 04. & 05. & \begin{tabular}{|l|l|}
06. & 0 \\
\end{tabular} & 07.10 & \begin{tabular}{l|l}
08. & 0 \\
\end{tabular} & 09. 1 & \begin{tabular}{l|l}
10. & 11. \\
\end{tabular} & \begin{tabular}{l|l|}
1. & 12. \\
\end{tabular} & 13. & 14. & 15. & 16. 11 & 17. 1 & 18. 1 & 19. & \begin{tabular}{l|l|}
20. & 21 \\
\end{tabular} & \begin{tabular}{l|l}
21. & 22. \\
\end{tabular} & \begin{tabular}{l|l}
2. & 23. \\
\end{tabular} & \begin{tabular}{l|l|}
3. & 24. \\
\end{tabular} & 25. & 26. & \begin{tabular}{|l|l|}
27. & 2 \\
\end{tabular} & \begin{tabular}{|l|l|l|}
28. & 2 \\
\end{tabular} & 29. & 30. \\
\hline \multirow{10}{*}{ Centro } & Alfredo Pedro Ribas & 2 & \begin{tabular}{|l|}
2 \\
\end{tabular} & & 2 & & \begin{tabular}{|l|l|}
2 & \\
\end{tabular} & & \begin{tabular}{l|l}
3,5 & 3 \\
\end{tabular} & \begin{tabular}{l|l|}
3,5 \\
\end{tabular} & & & & 3 & \begin{tabular}{l|l}
3 \\
\end{tabular} & & & & & \begin{tabular}{l|l}
3,5 & \\
\end{tabular} & \begin{tabular}{l|l}
3,5 \\
\end{tabular} & \begin{tabular}{|l|l|}
5 & 2 \\
\end{tabular} & \begin{tabular}{|l|} 
\\
\end{tabular} & 3,5 & 3,5 & \begin{tabular}{|l|l|l|}
2 & 0 \\
\end{tabular} & \begin{tabular}{|l|l|}
0,5 & \\
\end{tabular} & \begin{tabular}{l|l}
3 \\
\end{tabular} & 3 \\
\hline & Barão do Guaraúna & 3 & 3 & \begin{tabular}{l|l}
3 & 2 \\
\end{tabular} & 2,1 & 1 & 2 & & \begin{tabular}{l|l}
3,5 & 3 \\
\end{tabular} & 3,2 & 2 & 2 & & & 3,1 & & & & & 3,5 & 3 & \begin{tabular}{|l|}
3 \\
\end{tabular} & 4 & 3,2 & 2 & 1 & \begin{tabular}{l|l}
0,9 & 2 \\
\end{tabular} & 2,2 & 2,9 \\
\hline & Barão do Rio Branco & 2 & 2,3 & \begin{tabular}{|l|l|l|}
2,3 & 2 \\
\end{tabular} & 2,5 & 1,4 & 1,9 & & \begin{tabular}{l|l}
2,2 & 2 \\
\end{tabular} & 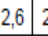 & \begin{tabular}{l|l}
2,6 & 2,1 \\
\end{tabular} & \begin{tabular}{|l|l|}
1 & 1,8 \\
\end{tabular} & & 1,8 & 2,3 & & 4 & 2 & 4 & \begin{tabular}{l|l}
2,3 & 1, \\
\end{tabular} & \begin{tabular}{l|l}
1,8 & 3 \\
\end{tabular} & 2,7 & \begin{tabular}{l|l|}
7 & 2,6 \\
\end{tabular} & \begin{tabular}{|l|} 
\\
\end{tabular} & 1 & 1 & \begin{tabular}{l|l}
1,5 & 2 \\
\end{tabular} & 2,8 & 2,6 \\
\hline & \begin{tabular}{|l} 
P. Amb. Gov. Manoel Ribas \\
a
\end{tabular} & 2,7 & $2 \mid$ & \begin{tabular}{|l|l|}
2,8 & 2 \\
\end{tabular} & 2,7 & 1 & 2,2 & & \begin{tabular}{l|l}
3,5 & 3 \\
\end{tabular} & \begin{tabular}{l|l}
3 & 2 \\
\end{tabular} & \begin{tabular}{l|l|}
2,5 & 3 \\
\end{tabular} & \begin{tabular}{|l|l|}
3 & \\
\end{tabular} & & 2 & & \begin{tabular}{l|l}
2,1 & 3 \\
\end{tabular} & 3,7 & 2 & 3 & & \begin{tabular}{l|l}
1,8 \\
\end{tabular} & \begin{tabular}{|l|l|}
8 & 1,8
\end{tabular} & \begin{tabular}{|l|l|}
8 & 4 \\
\end{tabular} & 2 & 2,3 & 2 & \begin{tabular}{c|c}
1 \\
1
\end{tabular} & 2 & 2,7 \\
\hline & Do Expedicionário & 3,5 & & 3 & & & & & \begin{tabular}{l|l}
3,8 & 3 \\
\end{tabular} & 3,5 & 3,1 & 1 & & 3 & & & & & & & 1,5 & \begin{tabular}{l|l|}
5 & 1,5 \\
\end{tabular} & \begin{tabular}{|l|l|}
5 & 3 \\
\end{tabular} & 3 & 2,5 & 2,1 & 0 & 0,5 & 1,5 \\
\hline & Duque de Caxias & 2,5 & & 2,5 & & & & & \begin{tabular}{l|l}
3,5 & 3 \\
\end{tabular} & 3,5 & 3,2 & 2 & & & 3,1 & & & & & & 3 & 2,5 & \begin{tabular}{|l|l|}
5 & 2,5 \\
\end{tabular} & \begin{tabular}{|l|}
5,6 \\
\end{tabular} & 2,6 & \begin{tabular}{|l|l}
2 & 0 \\
\end{tabular} & 0,9 & 3 & 3 \\
\hline & João Pessoa & 3,5 & & \begin{tabular}{|l|l}
2,5 & 2 \\
\end{tabular} & 2,9 & & & & \begin{tabular}{l|l}
3,5 & 3 \\
\end{tabular} & 3,4 & 3,5 & 5 & & & & & & & & & 2,8 & \begin{tabular}{l|l|}
8 & 2,7 \\
\end{tabular} & \begin{tabular}{l|l|}
7 & 4 \\
\end{tabular} & 3,5 & 3,6 & \begin{tabular}{|l|l|}
2,2 \\
\end{tabular} & \begin{tabular}{|l|l}
1 & 2 \\
\end{tabular} & 2,1 & 2,5 \\
\hline & Mal. Floriano Peixoto & 3,7 & 2,5 & 3,1 & 2 & & 1,8 & & \begin{tabular}{l|l}
3,1 & 3, \\
\end{tabular} & 3,2 & 2,5 & 5 & 2,2 & & 3 & & & & & 3 & 3,3 & \begin{tabular}{|l|l|}
3 & 3 \\
\end{tabular} & 3 & 2,8 & 2,5 & \begin{tabular}{|l|l|}
1,9 \\
\end{tabular} & 2 & 2,4 & 3,4 \\
\hline & Prof. Colares & 1,9 & & 2,1 & & & 2 & & \begin{tabular}{l|l}
2,3 & 2 \\
\end{tabular} & 2 & & & & 2 & & & & & & 3 & 1,5 & \begin{tabular}{|l|l|}
5 & 1 \\
\end{tabular} & 3,4 & \begin{tabular}{|l|}
2,3 \\
\end{tabular} & 3,1 & 2 & 0 & 0,3 & 0,9 \\
\hline & Santos Andrande & 2,4 & & \begin{tabular}{|l|l|}
3,3 & 2 \\
\end{tabular} & 2,5 & & & & \begin{tabular}{l|l}
2,5 & 2 \\
\end{tabular} & 2 & & & & & & & & & & & 3,5 & \begin{tabular}{l|l|}
5 & 2,1
\end{tabular} & \begin{tabular}{|l|l|}
1 & 2,5 \\
\end{tabular} & \begin{tabular}{|l|}
2,3 \\
\end{tabular} & 3,3 & \begin{tabular}{|l|l|}
2,92 \\
\end{tabular} & \begin{tabular}{|l|l}
2,1 & 3 \\
\end{tabular} & 3,6 & 2,7 \\
\hline \multirow{3}{*}{ Estrela } & Ângelo Moro & & 3,5 & & & & & & \begin{tabular}{l|l}
3,1 & 3 \\
\end{tabular} & 3,1 & & & & & & 3,3 & & & 1,5 & & 2,1 & \begin{tabular}{l|l}
1 & 2 \\
\end{tabular} & 2,5 & \begin{tabular}{|l|l|}
5 & 1,9 \\
\end{tabular} & 3 & 21 & \begin{tabular}{|l|l}
1,5 & 2 \\
\end{tabular} & 2,2 & 1,9 \\
\hline & Clube Serra de Ponta Grossa & & & & & & & & \begin{tabular}{l|l}
2,2 & $C$ \\
\end{tabular} & 0 & & & & & & & & & & & 0,9 & \begin{tabular}{l|l|}
9 & 0,9 \\
\end{tabular} & \begin{tabular}{|l|l|}
9 & 3,1 \\
\end{tabular} & 1,9 & 2,1 & \begin{tabular}{|l|l}
1,9 & 0 \\
\end{tabular} & \begin{tabular}{|l|l|}
0,9 \\
\end{tabular} & 0 & 0,3 \\
\hline & Margarida M. Moro & 2,5 & 2,5 & & 2,3 & & 1,5 & & \begin{tabular}{l|l}
2,5 & 2 \\
2
\end{tabular} & 2 & & & & 2 & 2,5 & & & & & 3 & 2,7 & \begin{tabular}{l|l|}
7 & 2 \\
\end{tabular} & \begin{tabular}{|l|} 
\\
\end{tabular} & 2,2 & 2,2 & \begin{tabular}{|l|l}
2 & 1 \\
\end{tabular} & \begin{tabular}{|l|l|}
1,2 & 2 \\
\end{tabular} & 2,5 & 2,8 \\
\hline \multirow{4}{*}{$\begin{array}{l}\text { Jd. } \\
\text { Carvalho }\end{array}$} & Bispo Ant?. Mazzaroto & 3,5 & 3,5 & & 1,5 & & & & \begin{tabular}{l|l}
3,8 & 3 \\
\end{tabular} & 3,5 & & & & 3,1 & & \begin{tabular}{l|l}
2,9 & 3 \\
\end{tabular} & \begin{tabular}{l|}
3,5 \\
\end{tabular} & 2 & 3,5 & & 3,7 & \begin{tabular}{l|l|}
7 & 3,2 \\
\end{tabular} & \begin{tabular}{|l|l|}
2 & 3,8 \\
\end{tabular} & \begin{tabular}{|l|}
3,5 \\
\end{tabular} & 3,5 & \begin{tabular}{|l|l|}
2,7 \\
\end{tabular} & \begin{tabular}{|l|l|}
1,7 & 2 \\
\end{tabular} & 2,8 & 2,9 \\
\hline & \begin{tabular}{|l|} 
Rotary Intermacional \\
\end{tabular} & 3,1 & & \begin{tabular}{|l|}
3,1 \\
\end{tabular} & 3 & & 1,5 & & \begin{tabular}{l|l}
3,5 & 3 \\
\end{tabular} & 3,4 & 3,4 & 4 & & 2 & 2,9 & & & & & 3 & 2,2 & \begin{tabular}{l|l|}
2 & 2,5 \\
\end{tabular} & \begin{tabular}{|l|l|}
5 & 3,1 \\
\end{tabular} & 3,3 & 3,6 & 2,1 & \begin{tabular}{|l|l}
1 & 1 \\
\end{tabular} & 1,9 & 2,1 \\
\hline & Dos Aposentados & & & & & & & & \begin{tabular}{l|l}
2,5 & 1 \\
\end{tabular} & 1,9 & & & & & & & & & & & 0 & 0 & 0 & 0 & 2,2 & 2,5 & 0 & 0 & 0 \\
\hline & João Maria Cordeiro & & 1,5 & & & & & & \begin{tabular}{l|l}
2 & 2 \\
\end{tabular} & 2 & & & & & & & & & & & 1,9 & \begin{tabular}{|l|l|}
9 & 0,8
\end{tabular} & \begin{tabular}{|l|l|}
8 & 2,2 \\
\end{tabular} & \begin{tabular}{|l|}
0,9 \\
\end{tabular} & 0,8 & 1 & \begin{tabular}{l|l}
0 & 0 \\
\end{tabular} & 0,8 & 0,5 \\
\hline \multirow{4}{*}{$\begin{array}{l}\text { Nova } \\
\text { Rússia }\end{array}$} & Cidade de Curitiba & 2,5 & 2,4 & & & & 1,5 & & \begin{tabular}{l|l}
2,2 & 2 \\
\end{tabular} & 2,1 & & & & & 2,2 & & & & & \begin{tabular}{l|l}
2,5 & 1, \\
\end{tabular} & \begin{tabular}{l|l}
1,9 & 1,8 \\
\end{tabular} & \begin{tabular}{|l|l|}
8 & 1,1 \\
\end{tabular} & \begin{tabular}{|l|l|}
1 & 3,1 \\
\end{tabular} & 3 & 3 & 2,50 & \begin{tabular}{|l|l|}
0,5 & 2 \\
\end{tabular} & 2,8 & 2,5 \\
\hline & Dom Pedro & 2,2 & & & & & 1,5 & & \begin{tabular}{l|l}
2,5 & 2 \\
\end{tabular} & 2,2 & 1,9 & 9 & & & & & & & & & \begin{tabular}{l|l|}
1,2 & 1,9 \\
\end{tabular} & \begin{tabular}{l|l|}
9 & 1,5 \\
\end{tabular} & \begin{tabular}{|l|l|}
5 & 3,2 \\
\end{tabular} & \begin{tabular}{|l|}
2,2 \\
\end{tabular} & 3 & 2,9 & \begin{tabular}{|l|l|}
0,5 \\
\end{tabular} & 2 & 1,9 \\
\hline & Getúlio Va & 3,8 & 3 & 3 & 2,9 & 1,9 & 1,9 & & \begin{tabular}{l|l}
3,1 & 3 \\
\end{tabular} & 3,1 & 3 & 3 & & 3,5 & 3,2 & 4 & & \begin{tabular}{l|l}
3,8 \\
\end{tabular} & 2 & 3 & \begin{tabular}{|l|l}
2,5 \\
\end{tabular} & \begin{tabular}{|l|l|}
5 & 2,5
\end{tabular} & \begin{tabular}{|l|l|}
5 & 3,3 \\
\end{tabular} & 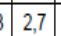 & 2,5 & 2,1 & \begin{tabular}{|l|l|}
1,9 & 2 \\
\end{tabular} & 2,9 & 2,5 \\
\hline & Prof. Álvaro Holzmann & 3,5 & 2 & & & & & & \begin{tabular}{l|l}
4 & 4 \\
\end{tabular} & 4 & & & & 3,5 & & & 4 & 2 & 3,5 & & 1,5 & \begin{tabular}{|l|l|}
5 & 1 \\
\end{tabular} & 2,5 & \begin{tabular}{|l|}
3,5 \\
\end{tabular} & 3,5 & 1,8 & \begin{tabular}{|l|l}
1 & 0 \\
\end{tabular} & 0,9 & 1,9 \\
\hline \multirow{7}{*}{ Oficinas } & Frei Elias Zull & 2,1 & 2 & 2 & & & & & \begin{tabular}{l|l}
3 & 2 \\
\end{tabular} & 2,9 & & & & & & & 2,9 & 2 & 2 & & 1,9 & \begin{tabular}{l|l}
9 & 1,5 \\
\end{tabular} & \begin{tabular}{|l|l|}
5 & 3 \\
\end{tabular} & 2 & 2,5 & \begin{tabular}{|l|l}
1,9 \\
\end{tabular} & \begin{tabular}{|l|l}
1 & 1 \\
\end{tabular} & 1,9 & 1,7 \\
\hline & Guairacá & 2 & 0,9 & & & & & & 2,5 & 1 & & & & & & & & & 1,1 & & 1,2 & \begin{tabular}{l|l|l|}
2 & 0,9 \\
\end{tabular} & \begin{tabular}{l|l|}
9 & 3 \\
\end{tabular} & 2 & 3,1 & 1 & \begin{tabular}{l|l}
2 & 1 \\
\end{tabular} & 1,1 & 1 \\
\hline & \begin{tabular}{|l|l} 
Igreja Lutera \\
\end{tabular} & & 1,5 & & & & & & \begin{tabular}{l|l}
3,1 & 3 \\
3
\end{tabular} & 3 & & & & & & & & & & & 0,2 & \begin{tabular}{l|l|}
2 & 1 \\
\end{tabular} & 3,8 & \begin{tabular}{|l|} 
\\
\end{tabular} & 3,5 & 2,5 & 0 & 0 & 0,4 \\
\hline & Isidoro Ferrer Alfaro & & 1 & & & & 1,1 & & \begin{tabular}{l|l}
2,1 & 2 \\
\end{tabular} & 2 & & & & 2,1 & & \begin{tabular}{l|l}
2 & 2 \\
\end{tabular} & \begin{tabular}{l|}
2,9 \\
\end{tabular} & 2 & 1,9 & & 0,3 & \begin{tabular}{|l|l|}
3 & 0 \\
\end{tabular} & 2,3 & \begin{tabular}{|l|l|}
3 & 1,8 \\
\end{tabular} & 2,2 & 20 & 0,5 & 0 & 0,2 \\
\hline & João Montes Filiho & 2,4 & 1,9 & & & 0 & 1,5 & & \begin{tabular}{l|l}
2,2 & 2 \\
\end{tabular} & 2 & & & & & & 2,1 & & & & 2,3 & 2,5 & \begin{tabular}{|l|l|}
5 & 2,1 \\
\end{tabular} & \begin{tabular}{|l|l|}
1 & 3 \\
\end{tabular} & 1 & 2 & 1,5 & 0 & 1,3 & 1,5 \\
\hline & Madre Maria dos & 3,5 & & \begin{tabular}{|l|l|l|l}
3,1 & 2 \\
\end{tabular} & 2,8 & & 1,5 & & \begin{tabular}{l|l}
3,6 & 3 \\
\end{tabular} & 3,5 & & & & & 2,9 & & & & & & 2,9 & \begin{tabular}{l|l|}
9 & 3 \\
\end{tabular} & 3,5 & \begin{tabular}{|l|l|}
5,9 \\
\end{tabular} & 4 & 2,3 & \begin{tabular}{l|l}
1 & 2 \\
\end{tabular} & 2,4 & 2,7 \\
\hline & Simäo BC & 2,7 & & 2,9 & & & 1,5 & & \begin{tabular}{l|l}
2,5 & 2 \\
\end{tabular} & 2,1 & 1,9 & 9 & & 2 & 2,1 & 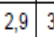 & 3,9 & 2 & 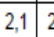 & 2,5 & 2,9 & \begin{tabular}{l|l|}
9 & 2,8
\end{tabular} & \begin{tabular}{|l|l|}
8 & 3,2 \\
\end{tabular} & \begin{tabular}{|l|}
2 \\
\end{tabular} & 2,5 & \begin{tabular}{|l|l|}
1,8 \\
\end{tabular} & 2 & 2,6 & 2,9 \\
\hline Olarias & Pedro Ribas & & & & & & & & \begin{tabular}{l|l}
1,9 & 0 \\
\end{tabular} & 0,9 & & & & & & & & & & & 0,9 & \begin{tabular}{l|l}
9 & 0,2 \\
\end{tabular} & \begin{tabular}{|l|l|}
2 & 2,9 \\
\end{tabular} & 0 & 1,9 & 1,10 & \begin{tabular}{|l|l|}
0,6 & 0 \\
\end{tabular} & 0,5 & 0,2 \\
\hline \multirow{3}{*}{ Órẫs } & Ana Batista & 2,2 & 0,9 & & & & & & \begin{tabular}{l|l}
3,5 & 3 \\
\end{tabular} & 3,5 & 0,9 & 9 & & & & & 3,5 & & & & 0,9 & \begin{tabular}{l|l}
9 & 0,5
\end{tabular} & \begin{tabular}{|l|l|}
5 & 3,5 \\
\end{tabular} & \begin{tabular}{|l|}
3,5 \\
\end{tabular} & 3,5 & \begin{tabular}{|l|l|}
1,8 \\
\end{tabular} & \begin{tabular}{|l|l}
1 & 0 \\
\end{tabular} & 0,9 & 0,7 \\
\hline & Săo José & & & 3,1 & & & & & \begin{tabular}{l|l}
3,1 & 3 \\
3
\end{tabular} & 3 & 4 & 4 & & & & & & & & & 2,2 & \begin{tabular}{|l|l|}
2 & 2,9
\end{tabular} & \begin{tabular}{|l|l|}
9 & 3,1 \\
\end{tabular} & \begin{tabular}{|l|}
4 \\
\end{tabular} & 4 & \begin{tabular}{|l|l|}
2,9 & \\
\end{tabular} & \begin{tabular}{|l|l}
1 & 1 \\
\end{tabular} & 1,9 & 2,2 \\
\hline & $\longdiv { \text { Lorival dos } }$ & & & & & & & & & & & & & & & 3,1 & & & & & 1,5 & \begin{tabular}{l|l|}
5 & 0,8
\end{tabular} & \begin{tabular}{|l|l|}
8 & 3 \\
\end{tabular} & 2 & 1,5 & \begin{tabular}{|l|l|}
1,6 \\
\end{tabular} & \begin{tabular}{|l|l|}
2 &
\end{tabular} & 0 & 0,5 \\
\hline \multirow{2}{*}{ Ronda } & Cel. Cristiar & & & & & & & & & & & & & & & & & & & & 0 & 0 & 3,1 & 3,1 & 3,1 & \begin{tabular}{|l|l}
3 & 0 \\
\end{tabular} & \begin{tabular}{|l|l|}
0,9 \\
\end{tabular} & 0 & 0 \\
\hline & Hilda Roedel & 3,3 & 1,8 & & & & & & \begin{tabular}{l|l}
3,5 & 3 \\
\end{tabular} & 3,1 & 0 & 0 & & 2,1 & & 3 & & & 2,2 & & 2,9 & \begin{tabular}{l|l}
9 & 2,5 \\
\end{tabular} & \begin{tabular}{|l|l|}
5 & 3,1 \\
\end{tabular} & 2 & 3 & \begin{tabular}{|c|}
1,9 \\
\end{tabular} & \begin{tabular}{|l|l}
1 & 2 \\
\end{tabular} & 2,3 & 2,5 \\
\hline \multicolumn{2}{|c|}{ NOTA TOTAL POR EQUIPAMENTOS } & 2,8 & 2,1 & \begin{tabular}{|l|l|l|l|l|}
2,8 & 2 \\
\end{tabular} & 2,4 & 1,3 & \begin{tabular}{l|l}
1,7 & 0 \\
\end{tabular} & \begin{tabular}{l|l}
0,02 \\
\end{tabular} & \begin{tabular}{l|l}
2,9 & 2 \\
\end{tabular} & 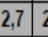 & \begin{tabular}{l|l}
2,6 & 2,5 \\
\end{tabular} & \begin{tabular}{l|l|}
5 & 1,8 \\
\end{tabular} & 2,2 & 2,5 & 2,8 & 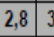 & $3,6=2$ & 2,2 & \begin{tabular}{l|l}
2,4 & 2 \\
\end{tabular} & \begin{tabular}{|l|l}
2,9 & 1,
\end{tabular} & \begin{tabular}{l|l}
1,6 & 2,1 \\
\end{tabular} & \begin{tabular}{|l|l}
1 & 1,8 \\
\end{tabular} & \begin{tabular}{|l|l|}
8,1 \\
\end{tabular} & 2,5 & \begin{tabular}{|l|}
2,7 \\
\end{tabular} & \begin{tabular}{|l|l|}
2,0 \\
\end{tabular} & \begin{tabular}{|l|l|}
1,0 & 1 \\
\end{tabular} & $\begin{array}{ll}1,6 \\
\end{array}$ & 1,8 \\
\hline \multicolumn{2}{|c|}{ CONCEITO"* } & $\mathrm{B}$ & \begin{tabular}{|l|}
$\mathrm{B}$ \\
\end{tabular} & \begin{tabular}{|l|l|}
$\mathrm{B}$ & \\
\end{tabular} & B & \begin{tabular}{|l|l}
$R$ \\
\end{tabular} & \begin{tabular}{l|l}
$\mathrm{R}$ & \\
\end{tabular} & & \begin{tabular}{l|l}
$\mathrm{B}$ & $\mathrm{E}$ \\
\end{tabular} & \begin{tabular}{l|l}
$\mathrm{B}$ & \\
\end{tabular} & \begin{tabular}{l|l} 
B & B \\
\end{tabular} & \begin{tabular}{|l|l|}
$B$ & $R$ \\
\end{tabular} & B & B & \begin{tabular}{l|l}
$\mathrm{B}$ \\
\end{tabular} & \begin{tabular}{l|l}
$\mathrm{B}$ & \\
\end{tabular} & \begin{tabular}{l|l}
0 \\
\end{tabular} & \begin{tabular}{l|l}
$R$ & \\
\end{tabular} & \begin{tabular}{l|l}
$\mathrm{B}$ & 1 \\
\end{tabular} & \begin{tabular}{l|l}
$\mathrm{B}$ & $\mathrm{R}$ \\
\end{tabular} & \begin{tabular}{l|l}
$R$ & $R$ \\
\end{tabular} & \begin{tabular}{|l|}
$R$ \\
\end{tabular} & 0 & B & \begin{tabular}{|l|}
$\mathrm{B}$ \\
\end{tabular} & \begin{tabular}{|l|}
$\mathrm{R}$ \\
\end{tabular} & \begin{tabular}{|l|l|}
$\mathrm{R}$ & \\
\end{tabular} & \begin{tabular}{l|l}
$R$ & \\
\end{tabular} & $\mathrm{R}$ \\
\hline \multicolumn{30}{|c|}{ 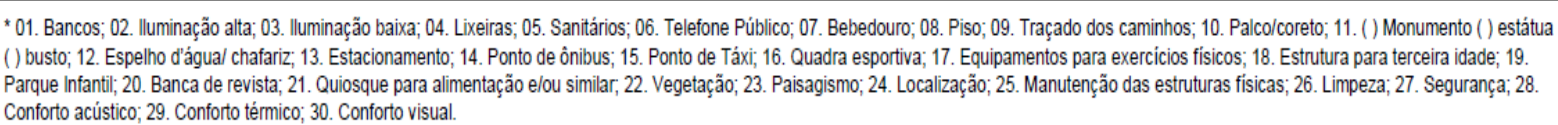 } \\
\hline
\end{tabular}

** $\mathrm{P}$ péssimo; $\mathrm{R}$ regular; $\mathrm{B}$ bom; $\mathrm{O}$ ótimo; - não houve nenhum equipamento para avaliar.

\section{CONCLUSÕES}

O resultado do levantamento quantitativo mostra que há uma grande diversidade de espécies presentes nas praças, porém muitas dessas espécies possuem apenas um indivíduo, denotando uma baixa abundância. $O$ número de espécies exóticas superou o número de espécies nativas o que propicia um desequilíbrio. 
O levantamento do porte arbóreo revelou um número alto de espécies de grande porte, fato que pode ser explicado em virtude das praças se configurarem como espaços estratégicos para o plantio desse porte, visto que dificilmente apresentam conflito com cabos de distribuição de energia ou com outras construções, porém o que não exclui necessariamente a existência desse tipo conflito nas praças. Em contrapartida verificou-se um baixo número mudas o que denota a baixa inserção de árvores nas praças.

No levantamento dos aspectos físicos das árvores foram obtidos resultados satisfatórios, pois a maioria dos indivíduos está em bom estado físico, porém há necessidades de podas de correção em muitas árvores.

Com o levantamento e avaliação dos equipamentos constatou-se um cenário heterogêneo, pois algumas praças possuem uma infraestrutura dotada de diversos equipamentos, portanto mais completa. Porém há praças que não apresentam nenhum equipamento como é o caso das praças Clube Serra de Ponta Grossa e Cel. Cristiano Justus Junior. O Parque Ambiental Gov. Manuel Ribas é dotado de uma diversificada infraestrutura, pode-se dizer que é o mais completo e que possui atrativos para todas as idades. Quanto à análise qualitativa da infraestrutura verificou-se que a maioria das estruturas existentes nas praças recebeu o conceito bom, verificando assim que, grande parte dos equipamentos não se encontram depredados em boa condição de uso para a população.

\section{REFERÊNCIAS}

AMBIENTE BRASIL. Disponível em: <www.ambientebrasil.com.br>. Acesso em: 02 out. de 2012.

BENETTI, H.A.D; HILGENBERG, F.J.S. A implantação de um programa de Arborização no Perímetro Central da Cidade de Ponta Grossa - PR. Monografia (Especialização em Gestão Ambiental). Universidade Estadual de Ponta Grossa, Paraná, 2001.

BOHNER, T.; GRACIOLI, C. R.; REDIN, C. G.; SILVA, D. T. da. Análise Quali-quantitativa da Arborização do Município de Guatambu, SC. Rev. Eletrônica do Curso de Especialização em Educação Ambiental da UFSM. Santa Maria-RS, v. 3, n 3, p. 532-546, 2011.

CALDEIRA, J. M. A Praça Brasileira: Trajetória de um Espaço Urbano: origem e modernidade. Tese (Doutorado em História) - Universidade Estadual de Campinas, Campinas, 2007. 
DE ANGELIS, B. L. D. A praça no contexto das cidades: o caso de Maringá PR. Tese (Doutorado) - Faculdade de Filosofia, Letras e Ciência Humanas, Universidade de São Paulo. São Paulo, 2000.

DE ANGELIS, B. L. D.; CASTRO, R. M.; DE ANGELIS NETO, G. Metodologia para levantamento, cadastramento, diagnóstico e avaliação de praças no Brasil. Rev. Engenharia civil, local, n.20, p. 57-70, 2004.

DE ANGELIS, B. L.; LOBODA, C. R. Áreas verdes públicas urbanas: conceitos, usos e funções. Ambiência, local, v.1, n. 1, p. 125-139 jan./jun. 2005.

GUZZO, P. Estudos dos espaços livres de uso público da cidade de Ribeirão Preto/SP, com detalhamento da cobertura vegetal e áreas verdes públicas de dois setores urbanos. Dissertação (Mestrado em Geografia) - Instituto de Geociências e Ciências Exatas, Universidade Estadual Paulista, Rio Claro, 1999.

INSTITUTO BRASILEIRO DE GEOGRAFIA E ESTATÍSTICA. Censo Demográfico 2010. Censo demogr., Rio de Janeiro, p. 1-239, 2010.

LIMA, A. M. L. P.; CAVALHEIRO, F.; NUCCI, J.C.; SOUZA, M.A.L.B.; FIALHO, N.O; DEL PICCHIA, P.C.D. Problemas de utilização na Conceituação de termos como espaços livres, áreas verdes e correlatos. In: CONGRESSO BRASILEIRO SOBRE ARBORIZAÇÃO URBANA, II, São Luiz/MA. Anais, p. 539-550, 1994. Disponível em: <http://www.geografia.ufpr.br/laboratorios/labs/arquivos/LIMA et al (1994).pdf>. Acesso em: 13 jun. de 2012.

LIMA, T. H. de S. O cotidiano nas praças assisenses: uma análise quali- quantitativa. Dissertação (Mestrado em Geografia). Universidade Estadual de Maringá, Maringá, 2006.

LORENZI, H., BACHER, L. B., SOUZA, H. M., TORRES, M. A. V. Árvores Exóticas do Brasil: madeiras ornamentais e aromáticas. Nova Odessa. SP: Instituto Plantarum, 2003.

LORENZI, H.; Árvores Brasileiras-Manual de Identificação e Cultivo de Plantas Arbóreas Nativas do Brasil- vol.2- Ed. Nova Odessa. SP: Instituto Plantarum, 1998b.

LORENZI. H.; Árvores Brasileiras-Manual de Identificação e Cultivo de Plantas Arbóreas Nativas do Brasil- vol.1- Ed. Nova Odessa. SP: Instituto Plantarum, 1998a.

MILANO, M.S.; DALCIN, E. Arborização de vias públicas. Rio de Janeiro: Light, 2000. $206 p$. 
MONASTIRSKY, L. B. Espaços Públicos em Ponta Grossa. Relatório de Pesquisa. Departamento de Geociências. UEPG. 2001.

MANTOVI, V. Áreas Verdes: uma percepção paisagística do refúgio biológico Bela Vista no meio urbano de Foz do Iguaçu. Monografia (Especialização Análise Ambiental e Regional em Geografia) - Universidade Estadual do Oeste do Paraná, Marechal Cândido Rondon, 2006.

MORO, D. A. Maringá Espaço e Tempo: ensaio de geografia urbana. Maringá. Programa de Pós-Graduação em Geografia - UEM, 2003.

RESENDE, T. M; SANTOS, D. G. dos. Avaliação quali-quantitativa da arborização das praças do bairro Jaraguá, Uberlândia - MG. Revista da Sociedade Brasileira de Arborização Urbana, Piracicaba-SP, v. 5, n. 2, p. 139-157, 2010.

SANTOS, N. R. Z. dos; TEIXEIRA, I. F. Arborização de vias públicas: Ambiente x Vegetação. Instituto Souza Cruz, 1aㅗ ed. Porto Alegre: Ed. Pallotti. 2001.

SANTOS, N. R. Z. dos; TEIXEIRA, I. F. Avaliação qualitativa da arborização da cidade de Bento Gonçalves, RS. Ciência Florestal, Santa Maria, v.1, n.1, p. 88-99, 1991. 